\title{
A systematic screening methodology towards exploration of ionic liquids for $\mathrm{CO}_{2}$ capture processes
}

\author{
Reza Farahipour, Amirhossein Mehrkesh, and Arunprakash T. Karunanithi* \\ Center for Sustainable Infrastructure Systems, University of Colorado Denver, Denver, CO- \\ 80217
}

\begin{abstract}
Reducing anthropogenic carbon dioxide emissions into atmosphere is an important and challenging goal as greenhouse gas emissions have been recognized as the major driver of climate change. In this context, researchers are studying the suitability of ionic liquids (ILs) as solvents for $\mathrm{CO}_{2}$ capture. Here, we propose a systematic, efficient, and quick IL screening methodology - for $\mathrm{CO}_{2}$ capture - by refining and using COSMO-RS as predictive thermodynamic model and integrating group contribution based feasibility constraints for viscosity and melting point. The methodology effectively considered different trade-offs and computationally evaluated hundreds of cation and anion combinations. The approach resulted in identification of 10 diverse and uncommon ILs with promising characteristics for $\mathrm{CO}_{2}$ absorption/desorption while possessing relatively low viscosity in comparison to more common ILs that have been studied before. These ILs also show significant potential for reducing process energy requirements. The results establish the effectiveness of the proposed methodology for exploration of novel IL candidates that have not been assessed previously.
\end{abstract}

\section{*Corresponding Author}

Phone: $303-556-2370$

Fax: 303-556-2368

E-mail: arunprakash.karunanithi@ucdenver.edu 


\section{Introduction}

Global climate change is one of the major contemporary challenges of mankind and it is directly connected to anthropogenic release of greenhouse gases (GHG). In this context, greater attention is being paid towards reduction of $\mathrm{CO}_{2}$ emissions into the atmosphere and a widely proposed strategy to realize this goal is carbon capture and storage (CCS). CCS requires selectively capturing $\mathrm{CO}_{2}$ from stationary sources such as power plants and storing it, primarily, in deep geological formations. Several techniques such as absorption, adsorption, membrane separation and cryogenic distillation are being investigated for $\mathrm{CO}_{2}$ capture while common storage options include deep-ocean injection, enhanced oil recovery, coal steam injection and aquifer injection ${ }^{1}$. Among the different strategies proposed for $\mathrm{CO}_{2}$ capture, absorption with regenerable solvents seems to be the most promising and feasible option ${ }^{2}$. Currently technologies that use aminebased solvents - e.g. monoethanolamine - are most developed for this purpose ${ }^{3}$. However, the energy intensive nature of this process, associated environmental impacts, solvent loss due to degradation and corrosion issues have led to the exploration of alternate solvents for this application ${ }^{4}$. In this regard, separating $\mathrm{CO}_{2}$ from industrial gases using ionic liquids is increasingly attracting significant attention ${ }^{5}$. Several ionic liquids have been found to possess high $\mathrm{CO}_{2}$ solubility ${ }^{6}$. Ionic liquids can be selected with an aim to promote physical absorption ${ }^{7}$ or chemical absorption ${ }^{8,9}$. ILs that undergo only physical absorption are more suited for separation processes that involve high $\mathrm{CO}_{2}$ partial pressures (e.g. pre-combustion capture) while ILs that promote chemisorption (in addition to physical absorption) are necessary for separation processes involving low $\mathrm{CO}_{2}$ partial pressures (e.g. post-combustion capture). Many researchers have suggested that in addition to possessing high $\mathrm{CO}_{2}$ solubility, ionic liquids, which have negligible vapor pressure, can be an effective green replacement for volatile organic solvents 
such as monoethanoamine. However, it is important to understand that such claims of greenness can only be ascertained through full life cycle assessment ${ }^{10,11}$. Another attractive feature of ionic liquids is its easy tunable nature due to availability of a large number of cation and anion combinations, making it possible to customize them for specific tasks ${ }^{12}$. Literature suggests that there are potentially $10^{16}$ ionic liquids that are theoretically possible 9 . This large number of IL structural variations cannot be evaluated experimentally and would require computational models that can analyze and screen them for application given task. In this context screening methods that employ completely predictive thermodynamic models are important as they may add significant value by reducing the time and cost associated with the identification and selection through trial and error experiments.

In this paper we present a systematic methodology towards computational screening of ILs for $\mathrm{CO}_{2}$ physical absorption. Employing this approach leads to fast prediction of relevant properties of a large number and wide variety of ionic liquids enabling us to narrow down to either specific class of ILs or to shortlist the most promising candidates that can further be validated through targeted experiments. In general, ILs have high viscosities in comparison to their molecular counterparts thereby greatly limiting their utility in several industrial applications, especially processes that require pumping. However, there are ILs that possess moderate viscosities that can be considered for these applications. This leads to another need of identifying low to moderately viscous ILs, in addition to the thermodynamic requirements of finding the best candidates for $\mathrm{CO}_{2}$ physical absorption. Another necessity is that the solvent (IL) needs to be in liquid state at operating conditions. This requirement further limits our options as several ILs exist in solid state at or near room temperature. Therefore, it is necessary to consider candidates that have melting point below the lower limit of the operating temperature range. The proposed 
methodology uses a systematic strategy to identify promising IL candidates by considering $\mathrm{CO}_{2}$ absorption/desorption capability, melting point, and viscosity of a large number of ionic liquids.

\section{Methods}

The main objective of this work was to develop a comprehensive methodology to down select promising ionic liquids with high capacity for physical absorption of $\mathrm{CO}_{2}$. In order for the selected ionic liquids to have practical application relevance we consider two other important characteristics namely low viscosity and low melting point. Further, not only do we consider high absorption capacity but are also interested in enhanced desorption at higher temperatures as this can greatly reduce the energy penalty. In order to efficiently perform the screening process

we defined an index (ADI) that captures both these aspects. According to Oexmann et al. ${ }^{13}$ the enthalpy of dissolution can be estimated using enthalpy of absorption with an acceptable error. The latter can be related to the change in Henry's constant with respect to temperature through van't Hoff equation as shown below.

$\Delta h_{d i s} \cong \Delta h_{a b s}=-R T^{2} \frac{d L n H}{d(T)}$

Where $\mathrm{H}$ relates to the Henry's constant. If we define $A D I^{\prime}$ as $\frac{H_{15}}{H_{45}}$ in a constant temperature interval the above equation can be rewritten as follows

$\Delta h_{d i s}=-R T^{2} \frac{\ln H_{45}-\ln H_{15}}{\Delta T}=-R T^{2} \frac{\ln \frac{H_{45}}{H_{15}}}{\Delta T}=R T^{2} \frac{\ln \frac{H_{15}}{H_{45}}}{\Delta T}=R T^{2} \frac{\ln A D I \prime}{\Delta T}$

This clearly shows that larger values of $A D I^{\prime}$ results in larger $\Delta h_{\text {dis }}$. Thus the proposed screening index should minimize $A D I^{\prime}$. In addition, as done in earlier studies ${ }^{14}$, to promote higher initial solubility it is crucial to consider ILs with lower Henry's constant at absorption temperature. 
Hence, we combined these two aspects and defined the overall absorption-desorption index (that needs to be minimized) as below:

$A D I=A D I^{\prime} \times H_{15}=\frac{H_{15}^{2}}{H_{45}}$

(Eqn.

3)

In this analysis we assumed that absorption always occurs at $15^{\circ} \mathrm{C}$ and desorption at $45^{\circ} \mathrm{C}$ for all screened ionic liquids. As ionic liquids generally have negligible vapor pressure, we define the Henry's constant of $\mathrm{CO}_{2}$ in an $\mathrm{IL}$ as $\mathrm{H}=p_{\mathrm{CO}_{2}}^{v a p} \times \gamma_{\mathrm{CO}_{2}}$ (Eqn. 4). The vapor pressure was calculated using Peng Robinson equation of State while the activity coefficient of $\mathrm{CO}_{2}$ in ionic liquid was calculated using COSMO-RS thermodynamic model ${ }^{15}$ implemented in $^{2}$ COSMOtherm $^{16}$.

COSMO-RS is a thermodynamic model, based on quantum chemistry, that can be used to estimate the chemical potential differences of molecules in liquids; i.e. $\mathrm{g}^{\mathrm{E}}$. Other properties such as solubility, activity or vapor pressure can be calculated using this chemical potential difference. Therefore, COSMO-RS is similar to other $\mathrm{g}^{\mathrm{E}}$ models such as UNIFAC and NRTL except that it is based on charge density surfaces generated by quantum chemical calculations. These charge densities are in fact descriptors that contain information on the electronic structure of the molecule as well as its interactions with neighboring molecules. The attractiveness of this method is that it is purely predictive in nature, is based on first principles, and does not require group parameters or any system-specific adjustments ${ }^{17}$.

In terms of thermodynamic calculations, COSMO-RS method has been reported to produce good qualitative results ${ }^{18}$ as well as satisfying quantitative predictions of activity coefficients of neutral compounds in ionic liquids. In addition, previous studies have validated COSMO-RS 
predictions using experimental solubility data ${ }^{19}$. All calculations in COSMOtherm were performed using BP level of DFT functional and TZVP basis set which are the recommended settings for prediction of thermophysical data needed for absorption applications ${ }^{20}$. All cations and anions considered for screening were from COSMOtherm ionic liquid database. This database consists of 212 cations and 63 anions resulting in 13356 ionic liquid combinations that can be evaluated. There are several parameterization sets - which have been refined and modified over the years - that are available within COSMOtherm for thermodynamic calculations. As a first step we examined which of these parameterization sets would work best for calculating the Henry's constant of ionic liquids for $\mathrm{CO}_{2}$ absorption. For this purpose, from literature, we assembled 68 experimental Henry's constants of different ILs and randomly selected 50 as part of a training set and the remaining as part of a test set. Then we calculated the Henry's constant for each system $\left(\mathrm{IL}+\mathrm{CO}_{2}\right.$ ) with different parameterization sets for BP-TZVP level and plotted the experimental versus predicted results for the four best sets (Figure 1.) which included the most recent set namely BP-TZVP-C21-1401. From Figure 1 we see that predictions based on BP_TZVP_C21_0108 parameterization set results in the best correlation (i.e. the highest $\mathrm{R}^{2}$ ). However, from Figure 1 we can also see that there is a systematic error between predicted and experimental values that needs correction. Hence, we chose the linear fit (Eqn. 5) based on BP_TZVP_C21_0108 set to reduce the systematic error associated with COSMOtherm predictions. In order to validate this correlation we calculated Henry's constants of the ILs in the test set first using parameterization set BP_TZVP_C21_0108 and next with the correlation (Eqn. 5)

$\mathrm{H}_{\text {mod }}=0.7403 \mathrm{H}_{\text {pred }}+7.9697$

(Eqn.

5) 
The comparison (Table 1) shows that the mean error reduced significantly from $37 \%$ to $13 \%$. Therefore to estimate ADI based on Henry's constant we used the following steps: 1) First activity coefficients of $\mathrm{IL}+\mathrm{CO}_{2}$ system was predicted by COSMOtherm; 2) The activity coefficient of $\mathrm{CO}_{2}$ was used to calculate the Henry's constant using Eqn. 4; 3) The Henry's constant was further adjusted for systematic errors through Eqn. 5; and 4) The above adjusted Henrys constant values were used to estimate the ADI using Eqn. 3.

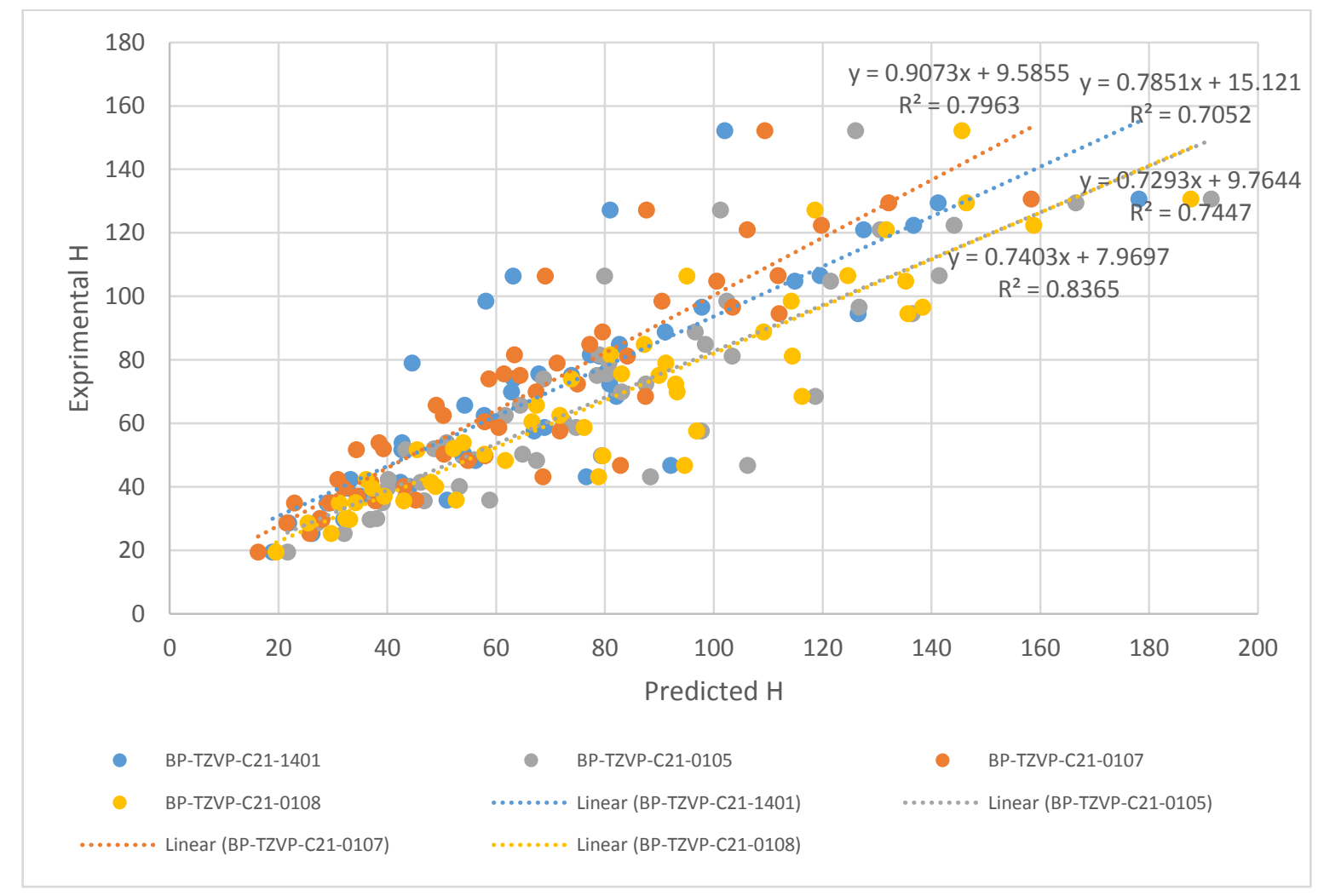

Figure 1- Experimental vs COSMOtherm predicted Henry's constant for the training set Table 1- Experimental, COSMOtherm predicated and modified Henry's constant for the test set

\begin{tabular}{|c|c|c|}
\hline $\mathbf{H}_{\mathbf{e x p}}$ & $\mathbf{H}_{\mathbf{1 0 8}}$ & $\mathbf{H}_{\mathbf{1 0 8}-\text { modified }}$ \\
\hline 57.8 & 76.09 & 64.30 \\
\hline 67.9 & 93.12 & 76.91 \\
\hline 77.0 & 112.60 & 91.33 \\
\hline 50.58 & 61.17 & 53.25 \\
\hline 57.49 & 68.98 & 59.04 \\
\hline
\end{tabular}




\begin{tabular}{|c|c|c|}
64.17 & 76.91 & 64.90 \\
\hline 69.35 & 85.45 & 71.23 \\
\hline 80.02 & 104.22 & 85.13 \\
\hline 103.38 & 136.98 & 109.37 \\
\hline 139.94 & 205.09 & 159.80 \\
\hline 47.46 & 60.83 & 53.00 \\
\hline 52.77 & 67.73 & 58.11 \\
\hline 57.28 & 75.30 & 63.71 \\
\hline 62.72 & 83.54 & 69.82 \\
\hline 71.26 & 101.29 & 82.95 \\
\hline 80.46 & 121.24 & 97.73 \\
\hline 94.18 & 155.87 & 123.36 \\
\hline 97.94 & 168.26 & 132.54 \\
\hline $\begin{array}{c}\text { Average } \\
\text { error }\end{array}$ & $\mathbf{3 6 . 6 \%}$ & $\mathbf{1 2 . 7 \%}$ \\
\hline
\end{tabular}

With respect to viscosity we utilized qualitative and quantitative findings from a recent study by Gharagheizi et al. ${ }^{21}$. This study focused on the development of a group contribution method based on a large data set consisting of 1672 viscosity data points covering different categories of ionic liquids making this method very reliable. Based on the model predictions the authors qualitatively analyzed the relationship between different cation/anion types and their viscosities. With regards to melting point predictions we used a group contribution method proposed by Lazzus $^{22}$. This model utilized melting point data of $200 \mathrm{ILs}$ to fit the contribution of anion and cation towards the IL melting point.

\section{Results and Discussion}

Applying Peng Robinson Equation of State with 50.83 bar and 99.29 bar for vapor pressure of $\mathrm{CO}_{2}$ at $15^{\circ} \mathrm{C}$ and $45^{\circ} \mathrm{C}$ respectively we converted activity coefficient values to Henry's constant using the following equation.

$H=\left[0.7403 \times\left(\gamma_{\text {cosmo }} \times P^{v a p}\right)+7.9697\right] \times \frac{\left(M_{\text {cat. }}+M_{\text {an. }}\right)}{1000}$

6) 
Based on Eqn. 6 it is clear that although many IL's possess high values of Henry's constant on a molarity scale, when converted to molality basis many will have low $\mathrm{H}$ values. Therefore, the search domain would by default narrow towards cations and anions that have low molecular weights.

Gharagheizi et al. ${ }^{21}$ did a comprehensive analysis of IL viscosities and concluded that there are four main categories of cations which possess low to moderate viscosity. These are Tri-alkyl imidazolium, sulfonium, pyridinium, and pyrrolidinium. Therefore we limited our search domain to these four cation types. By doing so the number of cations considered reduces to 69 , bringing down the number of binaries (ILs) to 4347 (69 x 63). Since estimating the Henry's constant in two different temperatures for each binary combination is extremely inefficient and unnecessary we further introduced a pre-screening step where we calculated the ADI for all of the 69 cations with a common anion $\mathrm{BF}_{4}^{-}$. This approach is justified as the COSMOtherm activity coefficient predictions are based on individual contributions of cation and anion separately. Therefore fixing an arbitrary anion will not have any influence on the trend related to cation effects on $\mathrm{CO}_{2}$ solubility. Through this step, we were able to down select 10 cations with the lowest ADI for further consideration.

Next, the ADI values were estimated for all (total of 630 ILs) ILs formed through the combination of the 10 selected cations and all of the 63 anions. The results were then sorted from the lowest ADI to the highest. Using this ADI sorted list as a reference, we picked the top 31 anions (i.e. 50\%) resulting in lowest ADI values for further consideration. Note that till this point we have taken into account, qualitatively, the effect of cation on viscosity but not that of anion. Therefore, the 31 anions were evaluated in using Ghareghizi's ${ }^{21}$ viscosity model and the top 20 anions with lowest contribution to IL viscosity were down selected to assure that the set of ILs 
further considered would have moderate or low viscosity while having favorable properties for $\mathrm{CO}_{2}$ absorption/desorption. The list comprised of ILs resulting from the combination of the 10 cations and 20 anions leading to a primary result matrix consisting of 200 candidates (Table 2). A cursory look at Table 2 shows that anions contribute more to the affinity of ILs towards $\mathrm{CO}_{2}$ compared to cations. Also worthy of note is the consistently low ADI values for ILs comprising anions such as acetate, dicyanamide and methylcarbonate.

Table 2- Primary matrix of calculated ADIs

\begin{tabular}{|c|c|c|c|c|c|c|c|c|c|c|}
\hline & $\begin{array}{c}\text { Tri } \\
\text { Et } \\
\text { Sul }\end{array}$ & $\begin{array}{l}1-\mathrm{Et} \\
1-\mathrm{Me} \\
\text { PYR }\end{array}$ & $\begin{array}{l}1,1- \\
\text { diPro } \\
\text { PYR }\end{array}$ & $\begin{array}{c}1,1- \\
\text { diMe } \\
\text { PYR }\end{array}$ & $\begin{array}{l}1-\mathrm{Bu} \\
1-\mathrm{Et} \\
\text { PYR }\end{array}$ & $\begin{array}{c}1-\mathrm{Et} \\
2,6- \\
\mathrm{diMe} \\
\text { PY }\end{array}$ & $\begin{array}{l}1-\mathrm{Me} \\
1 \text {-Pro } \\
\text { PYR }\end{array}$ & $\begin{array}{c}1,3 \mathrm{diE} \\
\mathrm{t} 4- \\
\mathrm{Me} \\
\mathrm{IM}\end{array}$ & $\begin{array}{c}\text { 4- } \\
\text { diMe } \\
\text { Amo } \\
1-E t \\
\text { PY }\end{array}$ & $\begin{array}{c}1-\mathrm{Bu} \\
3,5- \\
\text { diMe } \\
\text { PY }\end{array}$ \\
\hline acetate & 3.09 & 2.93 & 3.99 & 2.54 & 4.17 & 3.46 & 4.13 & 3.92 & 4.17 & 4.57 \\
\hline bismalonatoborate & 8.07 & 8.22 & 7.76 & 9.02 & 8.04 & 8.14 & 8.82 & 8.44 & 8.35 & 8.29 \\
\hline bisoxalatoborate & 7.80 & 8.21 & 7.15 & 9.52 & 7.36 & 7.79 & 8.08 & 7.81 & 7.69 & 7.44 \\
\hline $\begin{array}{l}\text { bis-pentafluoroethyl- } \\
\text { phosphinate }\end{array}$ & 6.02 & 5.99 & 5.99 & 6.18 & 6.14 & 6.56 & 7.20 & 6.62 & 6.73 & 6.76 \\
\hline bissalicylatoborate & 7.71 & 7.78 & 7.39 & 8.29 & 7.58 & 7.89 & 8.25 & 7.94 & 7.96 & 7.94 \\
\hline dibutylphosphate & 6.99 & 7.34 & 6.99 & 7.83 & 7.23 & 7.18 & 7.05 & 7.18 & 7.38 & 7.29 \\
\hline dicyanamide & 3.92 & 3.86 & 4.19 & 3.93 & 4.39 & 4.21 & 4.74 & 4.46 & 4.57 & 4.69 \\
\hline diethylphosphate & 5.68 & 5.85 & 5.88 & 6.14 & 6.12 & 5.91 & 6.22 & 6.05 & 6.25 & 6.27 \\
\hline dihydrogen-phosphate & 4.56 & 4.23 & 5.99 & 3.52 & 6.28 & 5.01 & 6.60 & 6.21 & 6.29 & 7.12 \\
\hline dimethylphosphate & 4.69 & 4.68 & 5.15 & 4.67 & 5.38 & 4.97 & 5.62 & 5.27 & 5.47 & 5.65 \\
\hline heptafluorobutanoate & 5.28 & 5.25 & 5.25 & 5.50 & 5.43 & 5.77 & 6.31 & 5.82 & 5.98 & 5.99 \\
\hline methylcarbonate & 3.49 & 3.34 & 4.20 & 3.06 & 4.41 & 3.83 & 4.52 & 4.23 & 4.45 & 4.76 \\
\hline salicylate & 5.32 & 5.34 & 5.35 & 5.67 & 5.57 & 5.54 & 6.09 & 5.72 & 5.82 & 5.95 \\
\hline saccharinate & 6.04 & 6.02 & 6.03 & 6.37 & 6.27 & 6.28 & 6.97 & 6.50 & 6.58 & 6.65 \\
\hline sbf6 & 5.46 & 5.83 & 5.07 & 6.86 & 5.23 & 5.98 & 6.72 & 5.65 & 5.69 & 5.48 \\
\hline tetrachloroaluminate & 6.38 & 7.38 & 6.46 & 8.17 & 6.53 & 6.75 & 6.84 & 6.53 & 6.50 & 6.34 \\
\hline tricyanomethane & 4.60 & 4.75 & 4.52 & 5.30 & 4.68 & 4.81 & 5.00 & 4.86 & 4.91 & 4.89 \\
\hline
\end{tabular}




\begin{tabular}{|l|c|c|c|c|c|c|c|c|c|c|}
\cline { 2 - 10 } trifluoroacetate & 4.13 & 4.07 & 4.33 & 4.18 & 4.54 & 4.55 & 5.23 & 4.75 & 4.88 & 5.01 \\
\hline $\begin{array}{l}\text { tris(nonafluorobutyl)trifluorop } \\
\text { hosphate }\end{array}$ & 9.32 & 9.25 & 9.61 & 9.15 & 9.66 & 9.96 & 11.80 & 9.86 & 10.04 & 10.11 \\
$\begin{array}{l}\text { tris(pentafluoroethyl)trifluorop } \\
\text { hosphate }\end{array}$ & 6.15 & 6.11 & 6.41 & 6.04 & 6.47 & 6.74 & 8.09 & 6.62 & 6.79 & 6.86 \\
\hline \begin{tabular}{l} 
acesulfamate \\
\hline
\end{tabular} & 5.54 & 5.62 & 5.62 & 5.98 & 5.84 & 5.78 & 6.63 & 6.01 & 6.06 & 6.16 \\
\hline
\end{tabular}

Tri Et Sul: Triethyl Sulfoniume; 1-Et 1-Me PYR: 1-Ethyl 1-Methyl Pyrrolidinium; 1,1-diPro PYR: 1,1-dipropyl Pyrrolidinium; 1,1-diMe PYR: 1,1-diMe Pyrrolidinium; 1-Bu 1-Et PYR: 1-Butyl 1-Ethyl Pyrrolidinium; 1-Et 2,6diMe PY: 1-Ethyl 2,6-diMethyl Pyridinium; 1-Me 1-Pro PYR: 1-Methyl 1-Propyl Pyrrolidinium; 1,3diEt 4-Me IM: 1,3-diEthyl 4-Methyl Imidazolium; 4-diMeAmo 1-Et PY: 4-diMethylAmino 1-ethyl Pyridinium; 1-Bu 3,5-diMe PY: 1-Butyl 3,5-diMethyl Pyridinium

At the next level, we applied the constraint of melting point lower than $270^{\circ} \mathrm{K}$ (calculated using Lazzús et al. ${ }^{22}$ GC approach) to the above result matrix (Table 2). As shown in Table 3, applying this constraint resulted in removal of several candidates that had shown initial promise for this application. This shows the importance of including holistic set of constraints for any IL selection problem. From Table 3, the top 10 ILs with the lowest ADI values were selected as the most promising candidates for further analysis. Table 4 lists these ILs along with their ADI values, and other predicted properties such as melting point, viscosity (at 298K), and heat capacity $\left(\mathrm{C}_{\mathrm{p}}\right)$ at $30^{\circ} \mathrm{C}$ (average of $15^{\circ} \mathrm{C}$ and $45^{\circ} \mathrm{C}$ ). For calculating heat capacity we used the group contribution method proposed by Valderrama et al. ${ }^{23} \mathrm{~A}$ flow chart that summarizes the proposed screening methodology is presented in Appendix.

Table 3- Primary matrix of calculated ADIs after applying melting point constraint

\begin{tabular}{|c|c|c|c|c|c|c|c|c|c|c|}
\hline & $\begin{array}{c}\text { Tri } \\
\text { Et }\end{array}$ & $\begin{array}{c}\text { 1-Et } \\
\text { 1-Me } \\
\text { Sul }\end{array}$ & $\begin{array}{c}1,1- \\
\text { diPro } \\
\text { PYR }\end{array}$ & $\begin{array}{c}1,1- \\
\text { diMe } \\
\text { PYR }\end{array}$ & $\begin{array}{c}1-\mathrm{Bu} \\
\text { 1-Et } \\
\text { PYR }\end{array}$ & $\begin{array}{c}\text { 1-Et } \\
\text { PiM } \\
\text { diM } \\
\text { e } \\
\text { PY }\end{array}$ & $\begin{array}{c}\text { 1-Me } \\
\text { 1-Pro } \\
\text { PYR }\end{array}$ & $\begin{array}{c}\text { 1,3diE } \\
\text { 4-Me } \\
\text { IM }\end{array}$ & $\begin{array}{c}\text { diMe } \\
\text { Amo } \\
\text { 1-Et } \\
\text { PY }\end{array}$ & $\begin{array}{c}\text { 1-Bu } \\
\text { 3,-diMe } \\
\text { PY }\end{array}$ \\
\hline acetate & 3.09 & & & & & & & 3.92 & & 4.57 \\
\hline bismalonatoborate & 8.07 & 8.22 & 7.76 & 9.02 & 8.04 & 8.14 & 8.82 & 8.44 & 8.35 & 8.29 \\
\hline bisoxalatoborate & 7.80 & 8.21 & 7.15 & 9.52 & 7.36 & 7.79 & 8.08 & 7.81 & 7.69 & 7.44 \\
\hline bis-pentafluoroethyl-phosphinate & 6.02 & & 5.99 & & 6.14 & 6.56 & & 6.62 & & 6.76 \\
\hline bissalicylatoborate & 7.71 & & & & & & & 7.94 & & 7.94 \\
\hline
\end{tabular}




\begin{tabular}{|c|c|c|c|c|c|c|c|c|c|c|}
\hline dibutylphosphate & 6.99 & 7.34 & 6.99 & 7.83 & 7.23 & 7.18 & 7.05 & 7.18 & 7.38 & 7.29 \\
\hline dicyanamide & 3.92 & & & & & & & & & 4.69 \\
\hline diethylphosphate & 5.68 & 5.85 & 5.88 & 6.14 & 6.12 & 5.91 & 6.22 & 6.05 & 6.25 & 6.27 \\
\hline dihydrogen-phosphate & 4.56 & 4.23 & 5.99 & 3.52 & 6.28 & 5.01 & 6.60 & 6.21 & 6.29 & 7.12 \\
\hline dimethylphosphate & 4.69 & 4.68 & 5.15 & 4.67 & 5.38 & 4.97 & 5.62 & 5.27 & 5.47 & 5.65 \\
\hline heptafluorobutanoate & 5.28 & & & & & & & & & 5.99 \\
\hline methylcarbonate & 3.49 & & 4.20 & & 4.41 & & & 4.23 & & 4.76 \\
\hline salicylate & 5.32 & & & & & & & & & 5.95 \\
\hline saccharinate & 6.04 & & & & & & & 6.50 & & 6.65 \\
\hline sbf6 & 5.46 & & & & & & & & & \\
\hline tetrachloroaluminate & 6.38 & & & & & & & & & 6.34 \\
\hline tricyanomethane & 4.60 & & & & & & & & & 4.89 \\
\hline trifluoroacetate & 4.13 & & & & & & & & & 5.01 \\
\hline $\begin{array}{l}\text { tris(nonafluorobutyl)trifluorophosp } \\
\text { hate }\end{array}$ & 9.32 & 9.25 & 9.61 & 9.15 & 9.66 & 9.96 & 11.80 & 9.86 & 10.04 & 10.11 \\
\hline $\begin{array}{l}\text { tris(pentafluoroethyl)trifluorophos } \\
\text { phate }\end{array}$ & 6.15 & 6.11 & 6.41 & 6.04 & 6.47 & 6.74 & 8.09 & 6.62 & 6.79 & 6.86 \\
\hline acesulfamate & 5.54 & 5.62 & 5.62 & 5.98 & 5.84 & 5.78 & 6.63 & 6.01 & 6.06 & 6.16 \\
\hline
\end{tabular}

Tri Et Sul: Triethyl Sulfoniume; 1-Et 1-Me PYR: 1-Ethyl 1-Methyl Pyrrolidinium; 1,1-diPro PYR: 1,1-dipropyl Pyrrolidinium; 1,1-diMe PYR: 1,1-diMe Pyrrolidinium; 1-Bu 1-Et PYR: 1-Butyl 1-Ethyl Pyrrolidinium; 1-Et 2,6diMe PY: 1-Ethyl 2,6-diMethyl Pyridinium; 1-Me 1-Pro PYR: 1-Methyl 1-Propyl Pyrrolidinium; 1,3diEt 4-Me IM: 1,3-diEthyl 4-Methyl Imidazolium; 4-diMeAmo 1-Et PY: 4-diMethylAmino 1-ethyl Pyridinium; 1-Bu 3,5-diMe PY: 1-Butyl 3,5-diMethyl Pyridinium

Table 4- Top 10 ILs and their thermophysical properties

\begin{tabular}{|l|c|c|c|c|c|c|}
\hline & $\begin{array}{c}\mathrm{H}_{15} \\
(\mathrm{bar})\end{array}$ & $\begin{array}{c}\mathrm{H}_{45} \\
(\mathrm{bar})\end{array}$ & $\begin{array}{c}\mathrm{ADI} \\
(\mathrm{bar})\end{array}$ & $\begin{array}{c}\mathrm{C}_{\mathrm{p}} \\
(\mathrm{KJ} / \mathrm{kg} . \mathrm{k})\end{array}$ & $\begin{array}{c}\text { Viscosity } \\
\text { Pa.s }\end{array}$ & $\begin{array}{c}\mathrm{T}_{\mathrm{m}} \\
(\mathrm{K})\end{array}$ \\
\hline Tri Et Sul Acetate & 5.70 & 10.50 & 3.09 & 1.933 & 0.017 & 244.53 \\
\hline Tri Et Sul Methylcarbonate & 6.42 & 11.81 & 3.49 & 1.857 & 0.018 & 218.47 \\
\hline 1,1-diMe PYR dihydrogen-phosphate & 7.13 & 14.43 & 3.52 & 1.648 & 0.146 & 258.06 \\
\hline 1,3-diEt 4-Me IM Acetate & 7.19 & 13.20 & 3.92 & 1.906 & 0.176 & 236.99 \\
\hline Tri Et Sul dicyanamide & 7.25 & 13.40 & 3.92 & 1.936 & 0.045 & 245.29 \\
\hline Tri Et Sul trifluoroacetate & 7.65 & 14.16 & 4.13 & 1.624 & 0.111 & 237.64 \\
\hline 1,1-diPro PYR Methylcarbonate & 7.48 & 13.33 & 4.20 & 1.941 & 0.038 & 271.36 \\
\hline 1-Et 1-Me PYR dihydrogen-phosphate & 8.30 & 16.31 & 4.23 & 1.680 & 0.097 & 254.31 \\
\hline 1,3-diEt 4-Me IM Methylcarbonate & 7.76 & 14.23 & 4.23 & 1.839 & 0.176 & 261.59 \\
\hline 1-Bu 1-Et PYR Methylcarbonate & 7.86 & 14.00 & 4.41 & 1.936 & 1.248 & 271.25 \\
\hline
\end{tabular}


As it is evident from table 4, the ranking order of ILs are not only dependent on low Henry's constant at the absorption temperature $\left(15^{\circ} \mathrm{C}\right)$ but are influenced by low ADIs which indirectly represents the optimal energetic efficiency of the overall process. For example 1, 1-dipro PYR methylcarbonate has a lower Henry's constant $\left(7.48\right.$ bar) at $15^{\circ} \mathrm{C}$ than that of Triethyl Sulfonium Trifluoroacetate ( 7.65 bar) at the same temperature but the relatively lower Henry's constant of 1, 1-dipro PYR Methylcarbonate at $45^{\circ} \mathrm{C}$ results in higher ADI compared to that of Triethyl Sulfonium Trifluoroacetate and brings it down in the overall ranking. It is also interesting to see that the top two ILs, Triethyl Sulfonium Acetate and Triethyl Sulfonium Methylcarbonate that have the lowest ADI values also possess the lowest viscosities.

In order to benchmark the effectiveness of these down selected ionic liquids - compared to common ILs - we analyzed their performance in relation to IL screening results from a very recent study by Zhang et al. ${ }^{24}$. In that study, the authors considered experimental data of 76 different conventional ILs and assessed their performance in terms of total energy requirements in a hypothetical carbon capture process. According to Zhang et al. ${ }^{24}$. this energy penalty can mainly be attributed to the IL regeneration step, which is related to both $\mathrm{CO}_{2}$ enthalpy of dissolution as well as the sensible heat needed to increase the temperature of $\mathrm{CO}_{2}$-IL solution (to the regenerator temperature) which is a direct function of heat capacity $\left(\mathrm{C}_{\mathrm{p}}\right)$ of the $\mathrm{IL}$ as shown in Eqn. 7 .

$$
Q_{\text {sens }}=n_{I L} C_{P, I L} \Delta T+n_{\mathrm{CO}_{2}} C_{p, \mathrm{CO}_{2}} \Delta T
$$

Since the enthalpy of dissolution is embedded within the definition of ADI we calculated the ADI of each proposed candidate from Zhang et al. ${ }^{24}$ (Table 5). Table 5 shows that compared to the IL's in our final set the ADI values of the ILs from Zhang et al. ${ }^{24}$, were on an average, higher 
by about $65 \%$ with a minimum ADI of 5.39 for [BmPy] [Tf2N] (compared to the minimum ADI of 3.09 for Triethyl Sulfonium Acetate from our study). This result shows that the enthalpy of dissolution for the regeneration step using ILs reported by Zhang et al. ${ }^{24}$ should be higher than those for ILs proposed in this study.

Table 5- Comparison of ADI values for different ionic liquids

\begin{tabular}{|c|c|c|c|}
\hline IL (Zhang et al. ${ }^{\mathbf{2 4}}$ ) & ADI (bar) & IL (this study) & ADI (bar) \\
\hline$[$ Emim] [Tf2N] & 7.12 & Tri Et Sul Acetate & 3.09 \\
\hline Bmim BF4 & 7.27 & Tri Et Sul Methylcarbonate & 3.49 \\
\hline BmimPF6 & 7.02 & 1,1-diMe PYR dihydrogen-phosphate & 3.52 \\
\hline Bmim Tf2N & 6.84 & 1,3-diEt 4-Me IM Acetate & 3.92 \\
\hline HmimTf2N & 7.01 & Tri Et Sul dicyanamide & 3.92 \\
\hline BmPy Tf2N & 5.39 & Tri Et Sul trifluoroacetate & 4.13 \\
\hline HmPy Tf2N & 5.56 & 1,1-diPro PYR Methylcarbonate & 4.20 \\
\hline & & 1-Et 1-Me PYR dihydrogen-phosphate & 4.23 \\
\hline & & 1,3-diEt 4-Me IM Methylcarbonate & 4.23 \\
\hline & & 1-Bu 1-Et PYR Methylcarbonate & 4.41 \\
\hline
\end{tabular}

With respect to sensible heat, we followed the same procedure proposed in Zhang et al. ${ }^{23}$ and calculated the sensible heat values for each of the 10 down selected ILs (Table 6). On an average, these values were $20 \%$ less in comparison to the ILs suggested in Zhang et al. ${ }^{23}$ In addition, it is also interesting to note that the IL Triethylsolfunium Acetate, in comparison to other ILs, really stands out in the sense that not only does it have the lowest ADI (enthalpy of dissolution) but also has the least sensible heat. Next, we show the comparison of the predicted viscosities at $298 \mathrm{~K}$ for the ILs shortlisted by Zhang et al. ${ }^{23}$ as their optimal candidates with the 
10 ILs selected in our study (Table 7). From Table 7 it is clear that, comparatively, the ILs proposed in this study generally have less viscosity.

Table 6- Sensible heat associated with IL as absorbent (GJ per ton of captured $\mathrm{CO}_{2}$ )

\begin{tabular}{|c|c|c|c|}
\hline $\begin{array}{c}\text { IL (Zhang et } \\
\text { al. }^{24} \text { ) }\end{array}$ & $\begin{array}{c}\text { Sensible heat } \\
\text { GJ/ton CO } \mathbf{~}_{\mathbf{2}}\end{array}$ & IL (this study) & $\begin{array}{c}\text { Sensible heat } \\
\mathbf{G J}_{\text {/ton }} \mathbf{C O}_{\mathbf{2}}\end{array}$ \\
\hline$[$ Emim] [Tf2N] & 0.501 & Tri Et Sul Acetate & 0.357 \\
\hline Bmim BF4 & 0.535 & Tri Et Sul Methylcarbonate & 0.374 \\
\hline BmimPF6 & 0.563 & 1,1-diMe PYR dihydrogen-phosphate & 0.514 \\
\hline Bmim Tf2N & 0.466 & 1,3-diEt 4-Me IM Acetate & 0.387 \\
\hline HmimTf2N & 0.519 & Tri Et Sul dicyanamide & 0.423 \\
\hline BmPy Tf2N & 0.641 & Tri Et Sul trifluoroacetate & 0.368 \\
\hline HmPy Tf2N & 0.361 & 1,1-diPro PYR Methylcarbonate & 0.368 \\
\hline & & 1-Et 1-Me PYR dihydrogen-phosphate & 0.516 \\
\hline & & 1,3-diEt 4-Me IM Methylcarbonate & 0.395 \\
\hline & & 1-Bu 1-Et PYR Methylcarbonate & 0.386 \\
\hline
\end{tabular}

Table 7- Viscosity comparison of ionic liquids

\begin{tabular}{|c|c|c|c|}
\hline $\begin{array}{c}\text { IL (Zhang et } \\
\text { al. }^{24} \text { ) }\end{array}$ & $\begin{array}{c}\text { Viscosity } \\
\text { Pa.s }\end{array}$ & IL (this study) & $\begin{array}{c}\text { Viscosity } \\
\text { Pa.s }\end{array}$ \\
\hline Emim Tf2N & 0.068 & Tri Et Sul Acetate & 0.017 \\
\hline Bmim BF4 & 0.0325 & Tri Et Sul Methylcarbonate & 0.018 \\
\hline BmimPF6 & 0.05 & 1,1-diMe PYR dihydrogen-phosphate & 0.146 \\
\hline Bmim Tf2N & 0.063 & 1,3-diEt 4-Me IM Acetate & 0.176 \\
\hline HmimTf2N & 0.085 & Tri Et Sul dicyanamide & 0.045 \\
\hline BmPy Tf2N & 0.273 & Tri Et Sul trifluoroacetate & 0.111 \\
\hline HmPy Tf2N & 0.108 & 1,1-diPro PYR Methylcarbonate & 0.038 \\
\hline & & 1-Et 1-Me PYR dihydrogen-phosphate & 0.097 \\
\hline & & 1,3-diEt 4-Me IM Methylcarbonate & 0.176 \\
\hline & & 1-Bu 1-Et PYR Methylcarbonate & 1.248 \\
\hline
\end{tabular}

\section{Conclusion}

Ionic liquids are an emerging category of chemicals that have shown promise as solvents for carbon capture processes. The ability to tune cation and anion structures provides a good 
platform for researchers to optimize their properties for $\mathrm{CO}_{2}$ absorption. This is a great opportunity but also presents a significant challenge as it is not possible to experimentally study the large number of possible IL combinations. In this paper we have presented a systematic approach that can overcome this problem by using computational methods as a screening strategy for successful selection of optimal ILs for $\mathrm{CO}_{2}$ capture. By making use of a first principles based predictive thermodynamic modeling and application of feasibility criteria, such as viscosity and melting point, we were able to quickly screen a large number of ILs for favorable $\mathrm{CO}_{2}$ capture properties. The methodology was able to systematically consider several thousand IL candidates resulting in a final shortlist of 10 ILs with promising characteristics. This list included diverse category of cations such as sulfonium, pyrolidinium, imidazolium, and pyridinium as well as different types of anions such as acetate, methylcarbonate, dihydrogen phosphate, and dicynamide thereby providing multiple options for further consideration. We believe that this approach adds significant value by lowering the time and costs associated with the experimental stage. It is proposed that further experimental work combined with process simulation studies can provide more insights on these promising ionic liquids in terms of their utility for $\mathrm{CO}_{2}$ capture.

\section{Author Information}

Corresponding Author

*E-mail: arunprakash.karunanithi@ucdenver.edu

\section{Acknowledgements}

This material is based upon work partially supported by the United States National Science Foundation (CAREER Program) under Grant No. 1151182. 


\section{Appendix}

Flow Chart of Ionic Liquid Screening Methodology for $\mathrm{CO}_{2}$ Capture 
Step 1: Identify subset of cation types (i.e. cation core) leading to low viscosity.

4 types of cation core (Tri-alkyl imidazolium, sulfonium, pyridinium, and pyrrolidinium) were identified.

69 out of 212 cations from COSMO database were of these 4 types and were selected for further analysis.

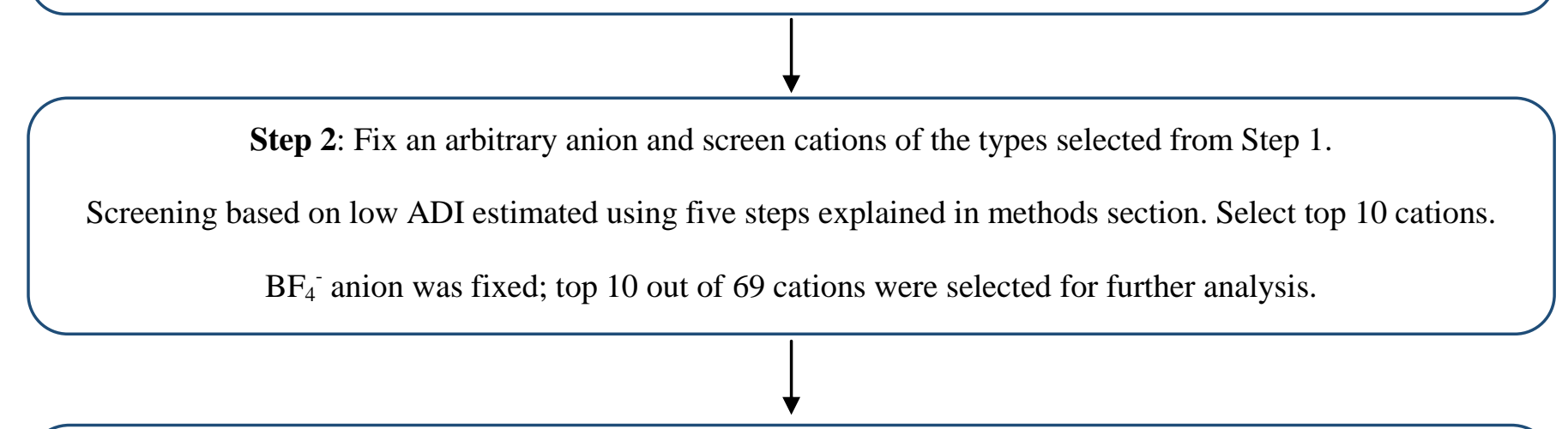

Step 3: Calculate ADI of all IL combinations based on all anions in COSMO database and the 10 down selected cations from step 2 . Select $50 \%$ of considered anions for further analysis.

630 different ILs (combination of 10 cations and 63 anions) were evaluated and 31 anions contributing to lower ADIs were selected.

Step 4: Screen down selected anions for low viscosity. Select top 20 anions leading to low viscosity.

20 anions were selected leading to 200 ILs (combination of 10 cations and 20 anions) for further consideration.

Step 5: Eliminate ILs with melting point $\left(\mathrm{T}_{\mathrm{m}}\right)$ higher than $270 \mathrm{~K}$.

Step 6: From the shortlist of step 5, select top 10 ILs with lowest ADIs, as the most promising candidates for further experimental evaluations.

\section{References}


1) Metz, Bert, et al. "Carbon dioxide capture and storage." (2005).

2) Yu, Cheng-Hsiu, Chih-Hung Huang, and Chung-Sung Tan. "A review of CO2 capture by absorption and adsorption." Aerosol and Air Quality Research 12.5 (2012): 745-769.

3) Rochelle, Gary T. "Amine scrubbing for CO2 capture." Science 325.5948 (2009): 1652-1654.

4) Rao, Anand B., and Edward S. Rubin. "A technical, economic, and environmental assessment of amine-based CO2 capture technology for power plant greenhouse gas control." Environmental science \& technology 36.20 (2002): 4467-4475.

5) Zhang, Xiangping, et al. "Carbon capture with ionic liquids: overview and progress." Energy \& Environmental Science 5.5 (2012): 6668-6681.

6) Ramdin, Mahinder, Theo W. de Loos, and Thijs JH Vlugt. "State-of-the-art of $\mathrm{CO}_{2}$ capture with ionic liquids." Industrial \& Engineering Chemistry Research51.24 (2012): 8149-8177.

7) Bara, Jason E., et al. "Guide to $\mathrm{CO}_{2}$ separations in imidazolium-based room-temperature ionic liquids." Industrial \& Engineering Chemistry Research 48.6 (2009): 2739-2751.

8) Bates, Eleanor D., et al. "CO2 capture by a task-specific ionic liquid." Journal of the American Chemical Society 124.6 (2002): 926-927.

9) Brennecke, Joan F., and Edward J. Maginn. "Ionic liquids: innovative fluids for chemical processing." American Institute of Chemical Engineers. AIChE Journal 47.11 (2001): 2384.

10) Farahipour, Reza, and Karunanithi, Arunprakash T. "Life Cycle Environmental Implications of $\mathrm{CO}_{2}$ Capture and Sequestration with Ionic Liquid 1-Butyl-3-methylimidazolium Acetate." ACS Sustainable Chemistry \& Engineering 2.11 (2014): 2495-2500.

11) Mehrkesh, Amirhossein, and Karunanithi, Arunprakash T. "Life cycle perspectives on aquatic ecotoxicity of common ionic liquids." Environ. Sci. Technol., (2015) DOI: 10.1021/acs.est.5b04721.

12) Karunanithi, Arunprakash T., and Amirhossein Mehrkesh. "Computer-aided design of tailor-made ionic liquids." AIChE Journal 59.12 (2013): 4627-4640.

13) Oexmann, Jochen, and Alfons Kather. "Minimising the regeneration heat duty of postcombustion CO 2 capture by wet chemical absorption: The misguided focus on low heat of absorption solvents." International Journal of Greenhouse Gas Control 4.1 (2010): 36-43.

14) Zhang, Xiaochun, Zhiping Liu, and Wenchuan Wang. "Screening of ionic liquids to capture CO2 by COSMO-RS and experiments." AIChE J. 54.10 (2008): 2717-2728.

15) Klamt, Andreas, Frank Eckert, and Wolfgang Arlt. "COSMO-RS: an alternative to simulation for calculating thermodynamic properties of liquid mixtures." Annual review of chemical and biomolecular engineering 1 (2010): 101-122.

16) Eckert, F., and A. Klamt. "COSMOtherm Version C3. 0, Release 13.01. COSMOlogic GmbH \& Co. KG, Leverkusen, Germany." Available at www. cosmologic.de (2013). 
17) Klamt, Andreas. COSMO-RS: From Quantum Chemistry to Fluid Phase Thermodynamics and Drug Design. Elsevier, 2005.

18) Banerjee, Tamal, Manish K. Singh, and Ashok Khanna. "Prediction of binary VLE for imidazolium based ionic liquid systems using COSMO-RS." Industrial \& engineering chemistry research 45.9 (2006): 3207-3219.

19) Zhou, T., Chen, L., Ye, Y., Chen, L., Qi, Z., Freund, H., Sundmacher, K. “An overview of mutual solubility of ionic liquids and water predicted by COSMO-RS." Industrial \& engineering chemistry research 51.17 (2012): 6256-6264.

20) Palomar, Jose, et al. "Understanding the physical absorption of $\mathrm{CO} 2$ in ionic liquids using the COSMO-RS method." Industrial \& Engineering Chemistry Research 50.6 (2011): 34523463.

21) Gharagheizi, Farhad, et al. "Development of a group contribution method for determination of viscosity of ionic liquids at atmospheric pressure." Chemical Engineering Science 80 (2012): 326-333.

22) Lazzús, Juan A. "A group contribution method to predict the melting point of ionic liquids." Fluid Phase Equilibria 313 (2012): 1-6.

23) Valderrama, José O., Alvaro Toro, and Roberto E. Rojas. "Prediction of the heat capacity of ionic liquids using the mass connectivity index and a group contribution method." The Journal of Chemical Thermodynamics 43.7 (2011): 1068-1073.

24) Zhang, Yingying, et al. "Screening of conventional ionic liquids for carbon dioxide capture and separation." Applied Energy (2015). 